\title{
Surgical increase in thoracic kyphosis increases unfused lumbar lordosis in selective fusion for thoracic adolescent idiopathic scoliosis
}

\author{
Jean-Luc Clément ${ }^{1}\left[\right.$ [ $\cdot$ Yann Pelletier ${ }^{1} \cdot$ Federico Solla $^{1} \cdot$ Virginie Rampal $^{1}$
}

Received: 30 March 2018 / Revised: 25 June 2018 / Accepted: 17 August 2018 / Published online: 11 September 2018

(c) The Author(s) 2018

\begin{abstract}
Purpose In adolescent idiopathic scoliosis (AIS), there is a close relationship between thoracic kyphosis (TK) and proximal lumbar lordosis (PLL). The hypothesis states correction of hypokyphosis increases lumbar lordosis (LL) through increase in PLL after surgical correction of TK.

Methods 111 consecutive thoracic AIS, Lenke 1 or 2 who underwent posterior selective thoracic fusion with reduction by simultaneous translation on 2 rods and 2 years follow-up have been prospectively selected and analyzed. Instrumentations below L1 and anterior releases were excluded. Global TK and LL were measured by a dedicated software. Mean values were compared through $T$ test, correlations assessed through Pearson's coefficient.

Results Global TK increased from $27^{\circ}$ to $46^{\circ}$ at the last follow-up $(p<0.0001)$ and LL from $58^{\circ}$ to $65^{\circ}(p<0.0001)$. PLL increased by $8^{\circ}\left(15^{\circ}-23^{\circ}\right)$, and distal lumbar lordosis remained stable $\left(42^{\circ}\right)$. The gains were higher for the Hypo-Kyphosis group than for the Normo-Kyphosis group $(p<0.001)$. There was a strong correlation (coef $=0.65$ ) between TK and PLL as well as between the gain of TK and the gain of PLL (coef $=0.70)$. LL increased after the first postoperative month. At 1 month, there was a significant increase in pelvic tilt and decrease in sacral slope, offsetting the LL increase, and indicating a temporary pelvic retroversion.

Conclusions Increase in TK led to increase in uninstrumented LL through increase in PLL with a continuous correlation between TK and PLL. These results allow surgeons to calculate the TK required during surgical correction of thoracic AIS to adapt LL to pelvic incidence.
\end{abstract}

Graphical abstract These slides can be retrieved under Electronic Supplementary Material.
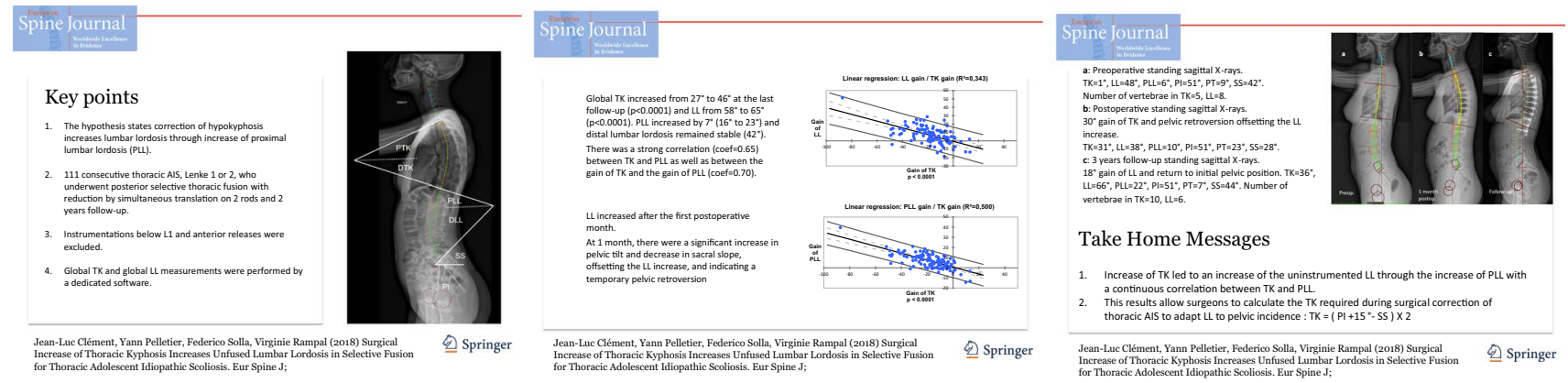

Keywords Adolescent idiopathic scoliosis · Thoracic kyphosis $\cdot$ Lumbar lordosis · Sagittal pelvic parameters · Thoracic selective fusion

Electronic supplementary material The online version of this article (https://doi.org/10.1007/s00586-018-5740-8) contains supplementary material, which is available to authorized users.

Extended author information available on the last page of the article 


\section{Introduction}

Hypokyphosis is a typical feature of adolescent idiopathic scoliosis (AIS). It is linked to the three-dimensional deformation of scoliosis. The thoracic scoliotic curve develops in an intermediate plane between the coronal and sagittal plane. Its sagittal projection results in a low thoracic kyphosis (TK). The correction of hypokyphosis remains difficult to obtain by modern instrumentation. Many publications have shown little evidence of significant variation or the decrease in TK after surgery with rotation of the rod, direct vertebral rotation, or cantilever reduction [1-6]. Conversely, translation techniques are more likely to improve TK [7-11]. It has been shown that the increase in TK by surgery leads to an increase in lumbar lordosis (LL) without correlation between reciprocal changes in TK and LL [12]. From the current literature, "Given the long-term importance of LL in maintaining sagittal balance, it seems prudent to increase TK and thus LL" [13]. In AIS, the hypokyphosis is correlated with a low LL, which is due to a low proximal lumbar lordosis (PLL). There is a close relationship between TK and PLL. The distal lumbar lordosis (DLL) remains related to pelvic incidence (PI) and sacral slope (SS) [14]. The aim of this work is to analyze how the surgical increase in TK effects LL and its two components, PLL and DLL, as well as pelvic parameters. The hypothesis is correction of hypokyphosis increases LL through increase in PLL.

\section{Methods}

\section{Patients}

Consecutive patients with thoracic AIS, Lenke type 1 or 2 were collected from a prospective data base, in a pediatric orthopedic center between 2010 and 2015. Patients underwent a posterior thoracic selective fusion and correction by simultaneous translation on 2 rods (ST2R) with a minimum of 24 months postoperative follow-up [8, 10, 11, 15]. Patients with instrumentation below L1 were excluded to better analyze the spontaneous evolution of uninstrumented LL. The rods were bent during the surgery according to the operator's experience and without proper planning apart from trying to adjust to the patient's pelvic incidence. Exclusion criteria included patients with additional anterior release. Patients were divided into two groups: Normo-Kyphosis group with normal preoperative TK greater than $20^{\circ}$ and, Hypo-Kyphosis group with preoperative TK less than $20^{\circ}$ [14].

\section{Radiographic measurements}

For all patients, full spine standing X-rays were performed preoperatively, 1 month postoperatively and at the last follow-up as a part of the routine evaluation of the scoliosis cases.

The lateral radiographs were taken on the same medical imaging network in standing position with the arm lying horizontally, hand on a support and visualizing the entire spine from the auditive canals to the proximal extremity of the femurs. All the measurements were performed automatically by the software "Keops Analyser" after graphic identification of landmarks (femoral heads, sacral plate, iliac wings, coracoids, etc.), vertebrae, and sagittal curves, established by the same surgeon (JLC). This digital measurement method is superior to the direct measurement on X-rays [16].

The global thoracic kyphosis was calculated by measuring the totality of the vertebrae in kyphosis independent of a fixed vertebral level. The global TK is defined by two inflection points: the superior point between TK and cervical lordosis, and the inferior point between TK and LL. Similarly, global lumbar lordosis was measured by the point of inflection between TK and LL and the sacral plate [17]. We noted the level of the inflection point between the curves, as well as the number of vertebrae in each of the sagittal curves.

According to Vaz and Roussouly [18], LL was divided into proximal and distal LL. In a same way, TK was divided into proximal and distal TK (Fig. 1). Proximal thoracic kyphosis (PTK) is the angle between the horizontal line and the inflexion point between TK and cervical lordosis. PTK is the part of the kyphosis lying over the horizontal line independently to a vertebral level. Distal thoracic kyphosis (DTK) is the angle between the horizontal line and the inflexion point between TK and LL. DTK is the part of the kyphosis lying under the horizontal line independently to a vertebral level. DTK is geometrically equivalent to PLL.

The sagittal balance was measured by the C7 Plumb lineS1 distance.

\section{Statistical analysis}

Mean values were compared through paired or impaired $T$ test. Correlations were assessed through Pearson's correlation coefficient or linear regressions. Significance level was set at 0.05. All analyses were performed with XLStat Addinsoft ${ }^{\circledR}$.

\section{Ethics}

All procedures were in accordance with the ethical standards of the institutional research committee and with the 1964 Declaration of Helsinki and its later amendments or comparable ethical standards. This study has been approved by the authors' Institutional Review Board (IRB): French 


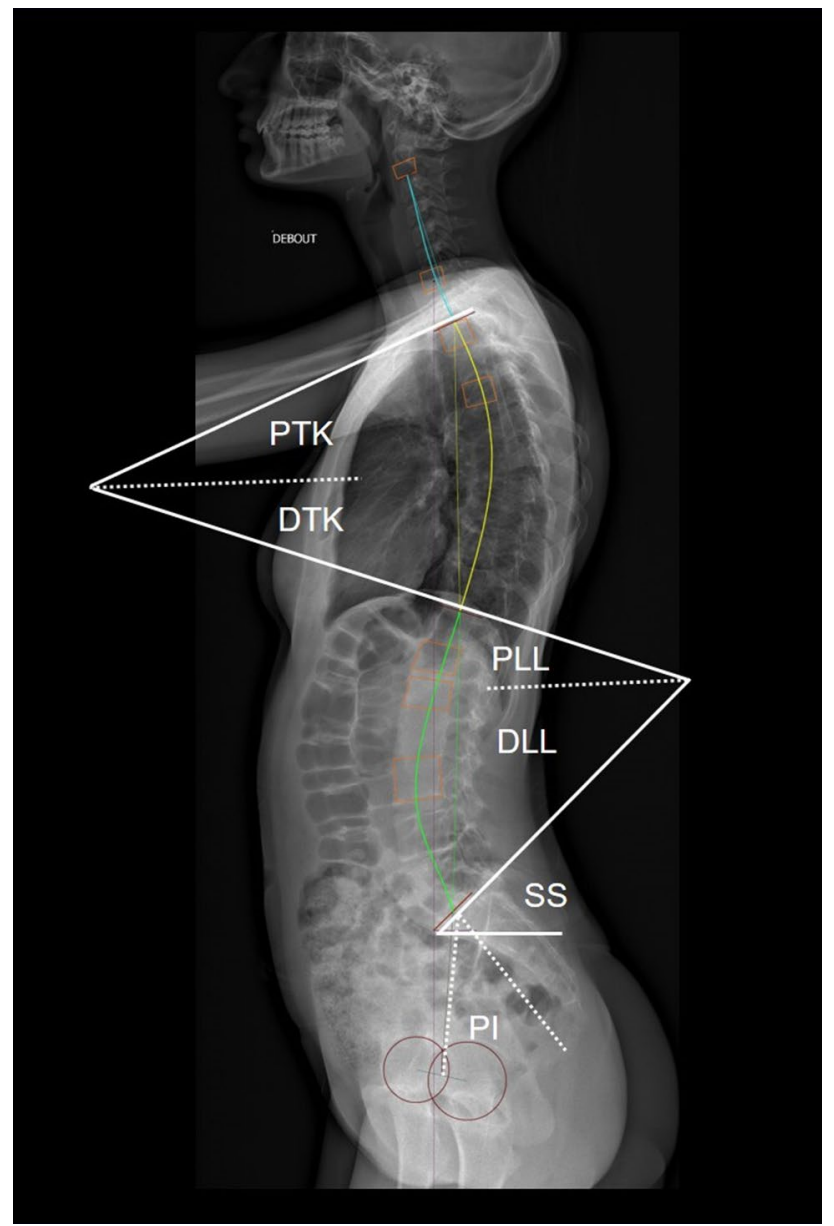

Fig. 1 Measurements of global thoracic kyphosis and global lumbar lordosis. TK is limited by two inflection points, one superior between TK and cervical lordosis, the other inferior between TK and LL. LL is limited by the point of inflection between TK and LL and the sacral slope. PTK proximal thoracic kyphosis, DTK distal thoracic kyphosis, $P L L$ proximal lumbar lordosis, $D L L$ distal lumbar lordosis, $S S$ sacral slope, $P I$ pelvic incidence. $\mathrm{DTK}=\mathrm{PLL} ; \mathrm{DLL}=\mathrm{SS}$
CPP (committee for the protection of persons) with number 2012-A01663-40, ref 13.003, and protocol 72082012 . Informed written consent by both parents and patients has been obtained.

\section{Results}

With a total of 111 patients, 32 in the Hypo-Kyphosis group and 79 in the Normo-Kyphosis group were included. The mean follow-up was 64 months (24-175). In the coronal plane, the main thoracic curve decreased from $52^{\circ}\left(35^{\circ}-80^{\circ}\right)$ to $16^{\circ}\left(1^{\circ}-36^{\circ}\right)$ at follow-up which correspond to an average correction of $69 \%$.

\section{Sagittal results}

In the whole cohort (Table 1 ), TK increased from $27^{\circ}$ to $46^{\circ}$ at the last follow-up $(p<0.0001)$ and LL from $58^{\circ}$ to $65^{\circ}(p<0.0001)$. PLL increased by $8^{\circ}$, while DLL remained stable.

In the Hypo-Kyphosis group (Table 2), TK increased from $7^{\circ}$ preoperatively to $41^{\circ}$ at last follow-up $(p<0.0001)$ and $\mathrm{LL}$ from $53^{\circ}$ to $66^{\circ}(p<0.0001)$. PLL increased by $12^{\circ}$, while DLL remained stable.

In the Normo-Kyphosis group (Table 3), TK increased from $36^{\circ}$ preoperatively to $48^{\circ}$ at last follow-up $(p<0.0001)$ and LL from $60^{\circ}$ to $64^{\circ}(p<0.0001)$. PLL increased by $5^{\circ}$, while DLL remained stable.

Increase in TK, LL, and PLL in Hypo-Kyphosis group was higher than in Normo-Kyphosis group $(p<0.001)$.

Tables 1, 2, and 3 show the values of the sagittal pelvic and spinal parameters for the whole cohort and for the two groups.

Table 1 Values of sagittal pelvic and spinal parameters for the whole cohort

\begin{tabular}{|c|c|c|c|c|c|c|}
\hline Whole cohort & $\begin{array}{l}\text { Preoperative mean } \\
\text { value (min; max) }\end{array}$ & $\begin{array}{l}\text { Postoperative mean } \\
\text { value (min; } \max \text { ) }\end{array}$ & $\begin{array}{l}\text { Follow-up mean } \\
\text { value (min; max) }\end{array}$ & $\begin{array}{l}p \\
\text { Pre-op/post-op }\end{array}$ & $\begin{array}{l}p \\
\text { Pre-op/follow-up }\end{array}$ & $\begin{array}{l}p \\
\text { Post-op/follow-up }\end{array}$ \\
\hline TK $\left(^{\circ}\right)$ & $27(-12 ; 64)$ & $43(25 ; 66)$ & $46(19 ; 69)$ & $<0.001$ & $<0.001$ & $<0.001$ \\
\hline $\mathbf{L L}\left({ }^{\circ}\right)$ & $58(34 ; 80)$ & $59(36 ; 84)$ & $65(35 ; 99)$ & NS & $<0.001$ & $<0.001$ \\
\hline PLL $=$ DTK $\left(^{\circ}\right)$ & $15(-10 ; 36)$ & $20(-2 ; 33)$ & $23(12 ; 35)$ & $<0.001$ & $<0.001$ & $<0.001$ \\
\hline $\mathbf{D L L}=\mathbf{S S}\left(^{\circ}\right)$ & $42(20 ; 68)$ & $39(21 ; 65)$ & $42(15 ; 69)$ & $<0.001$ & NS & $<0.001$ \\
\hline $\mathbf{P I}\left(^{\circ}\right)$ & $51(25 ; 82)$ & $50(21 ; 82)$ & $50(11 ; 83)$ & NS & NS & NS \\
\hline PT $\left(^{\circ}\right)$ & $8(-8 ; 31)$ & $11(-6 ; 29)$ & $8(-10 ; 27)$ & $<0.001$ & NS & $<0.001$ \\
\hline LL-PI $\left(^{\circ}\right)$ & $7(-24 ; 31)$ & $9(-13 ; 29)$ & $15(-5 ; 40)$ & NS & $<0.001$ & $<0.001$ \\
\hline C7-S1 (mm) & $-4(-96 ; 73)$ & $0(-68 ; 90)$ & $-6(-53 ; 39)$ & NS & NS & NS \\
\hline Vertebrae in $\mathbf{L L}$ (n) & $6(3 ; 10)$ & $5(4 ; 8)$ & $5(4 ; 7)$ & $<0.001$ & $<0.001$ & NS \\
\hline Vertebrae in TK (n) & $9(3 ; 13)$ & $10(8 ; 13)$ & $10(8 ; 12)$ & $<0.001$ & $<0.001$ & NS \\
\hline
\end{tabular}

$T K$ thoracic kyphosis, $L L$ lumbar lordosis, $P L L$ proximal lumbar lordosis, $D T K$ distal thoracic kyphosis, $D L L$ distal lumbar lordosis, $S S$ sacral slope, $P I$ pelvic incidence, $P T$ pelvic tilt

Bold is used for significant values 
Table 2 Values of sagittal pelvic and spinal parameters for the Hypo-Kyphosis group

\begin{tabular}{|c|c|c|c|c|c|c|}
\hline Hypo-Kyphosis group & $\begin{array}{l}\text { Preoperative mean } \\
\text { value (min; max) }\end{array}$ & $\begin{array}{l}\text { Postoperative mean } \\
\text { value (min; } \max \text { ) }\end{array}$ & $\begin{array}{l}\text { Follow-up mean } \\
\text { value (min; } \max \text { ) }\end{array}$ & $\begin{array}{l}p \\
\text { Pre-op/post-op }\end{array}$ & $\begin{array}{l}p \\
\text { Pre-op/follow-up }\end{array}$ & $\begin{array}{l}p \\
\text { Post-op/follow-up }\end{array}$ \\
\hline $\mathrm{TK}\left({ }^{\circ}\right)$ & $7(-12 ; 20)$ & $39(25 ; 60)$ & $41(20 ; 57)$ & $<0.001$ & $<0.001$ & 0.04 \\
\hline $\operatorname{LL}\left({ }^{\circ}\right)$ & $53(34 ; 80)$ & $60(36 ; 84)$ & $66(45 ; 99)$ & NS & $<0.001$ & $<0.001$ \\
\hline $\operatorname{PLL}=\operatorname{DTK}\left({ }^{\circ}\right)$ & $10(-10 ; 19)$ & $17(-1 ; 28)$ & $22(13 ; 35)$ & $<0.001$ & $<0.001$ & $<0.001$ \\
\hline $\mathrm{DLL}=\mathrm{SS}\left({ }^{\circ}\right)$ & $43(19 ; 68)$ & $42(21 ; 65)$ & $44(31 ; 69)$ & NS & NS & 0.005 \\
\hline $\operatorname{PI}\left({ }^{\circ}\right)$ & $52(28 ; 83)$ & $53(30 ; 82)$ & $52(27 ; 83)$ & NS & NS & NS \\
\hline $\mathrm{PT}\left({ }^{\circ}\right)$ & $9(-5 ; 21)$ & $11(-1 ; 26)$ & $8(-6 ; 27)$ & NS & NS & $<0.001$ \\
\hline LL-PI $\left(^{\circ}\right)$ & $1(-21 ; 24)$ & $6(-13 ; 27)$ & $14(-5 ; 40)$ & 0.04 & $<0.001$ & $<0.001$ \\
\hline C7-S1 (mm) & $-4(-47 ; 73)$ & $3(-68 ; 58)$ & $-6(-53 ; 30)$ & NS & NS & NS \\
\hline Vertebrae in LL (n) & $7(4 ; 9)$ & $5(4 ; 8)$ & $5(4 ; 7)$ & $<0.001$ & 0.001 & NS \\
\hline Vertebrae in TK (n) & $7(3 ; 13)$ & $10(6 ; 12)$ & $10(8 ; 12)$ & $<0.001$ & $<0.001$ & NS \\
\hline
\end{tabular}

Bold is used for significant values

Table 3 Values of sagittal pelvic and spinal parameters for the Normo-Kyphosis group

\begin{tabular}{|c|c|c|c|c|c|c|}
\hline Normo-Kyphosis group & $\begin{array}{l}\text { Preoperative mean } \\
\text { value (min; max) }\end{array}$ & $\begin{array}{l}\text { Postoperative mean } \\
\text { value ( } \min ; \max )\end{array}$ & $\begin{array}{l}\text { Follow-up mean } \\
\text { value (min; max) }\end{array}$ & $\begin{array}{l}p \\
\text { Pre-op/post-op }\end{array}$ & $\begin{array}{l}p \\
\text { Pre-op/follow-up }\end{array}$ & $\begin{array}{l}p \\
\text { Post-op/follow-up }\end{array}$ \\
\hline $\operatorname{TK}\left({ }^{\circ}\right)$ & $36(20 ; 64)$ & $45(27 ; 66)$ & $48(23 ; 70)$ & $<0.001$ & $<0.001$ & $<0.001$ \\
\hline $\operatorname{LL}\left({ }^{\circ}\right)$ & $60(41 ; 80)$ & $59(39 ; 82)$ & $64(35 ; 91)$ & NS & 0.002 & $<0.001$ \\
\hline PLL $=$ DTK $\left(^{\circ}\right)$ & $18(6 ; 36)$ & $21(9 ; 33)$ & $23(12 ; 33)$ & 0.001 & $<0.001$ & $<0.001$ \\
\hline $\mathrm{DLL}=\mathrm{SS}\left({ }^{\circ}\right)$ & $42(22 ; 62)$ & $38(21 ; 59)$ & $41(15 ; 62)$ & 0.004 & NS & $<0.001$ \\
\hline $\mathrm{PI}\left({ }^{\circ}\right)$ & $50(25 ; 70)$ & $49(21 ; 70)$ & $49(11 ; 72)$ & NS & NS & NS \\
\hline $\mathrm{PT}\left({ }^{\circ}\right)$ & $8(-9 ; 31)$ & $11(-6 ; 29)$ & $8(-10 ; 21)$ & 0.02 & NS & $<0.001$ \\
\hline LL-PI $\left(^{\circ}\right)$ & $10(-31 ; 12)$ & $9(-9 ; 29)$ & $15(-5 ; 40)$ & NS & $<0.001$ & $<0.001$ \\
\hline C7-S1 (mm) & $-5(-96 ; 50)$ & $-2(-59 ; 90)$ & $-5(-49 ; 39)$ & NS & NS & NS \\
\hline Vertebrae in LL (n) & $6(3 ; 10)$ & $5(4 ; 7)$ & $5(4 ; 7)$ & 0.02 & $<0.001$ & NS \\
\hline Vertebrae in TK (n) & $10(4 ; 13)$ & $10(8 ; 13)$ & $10(8 ; 12)$ & NS & NS & NS \\
\hline
\end{tabular}

Bold is used for significant values

\section{Correlations and linear regressions}

There was a strong correlation between PLL and TK preoperatively (Pearson's coefficient $=0.69$ ) and at last follow-up (Pearson's coefficient $=0.64$ ) (Fig. 2). Correlations between TK and LL were weak, both preoperatively and at last follow-up (Pearson's coefficient $=0.34$ and 0.32 ).

From linear regressions (Fig. 3), the gain of PLL significantly correlated with the gain of TK (Pearson's coefficient $=0.7)($ PLL gain $=0.34 *$ TK gain $)$ as well as the gain of LL (LL gain $=0.4 *$ TK gain).

\section{Discussion}

The increase in TK from AIS surgery resulted in an increase in LL through the increase in PLL $\left(8^{\circ}\right)$. Thus, the hypothesis is accepted.
This is explained by the geometric construction that divides lordosis and kyphosis into two proximal and distal parts (Fig. 1). The transitional vertebra between DTK and PLL is the point where the curves are reversed. Increasing the slope of this transitional vertebra by improvement of TK from the surgery automatically induces an increase in PLL.

There is a strong and continuous correlation between TK and PLL due to the geometric equivalence between DTK and PLL. The equation, LL gain $=0.4 *$ TK gain, means $40 \%$ of the gain on TK is transferred to gain on LL through the increase in the slope of the transitional vertebra. The remaining $60 \%$ concerns the PTK. We assume that a similar geometrical construction could be extended to the cervical spine with the PTK being equivalent to the distal cervical lordosis. Thus, the increase in PTK could improve cervical lordosis.

The gain in LL is greater for the hypokyphosis group $\left(13^{\circ}\right)$ than for the normal kyphosis group $\left(4^{\circ}\right)$, the final targeted TK for all patients being the same.

A contemporary LL and TK increase during anterior [19] or posterior fusion has been reported [10, 12]. However, no 
Fig. 2 Linear regression between PLL and TK preoperatively and at follow-up. $P L L$ proximal lumbar lordosis, $T K$ thoracic kyphosis, $F$-up follow-up
Linear régression : Preoperative PLL / PreoperatriveTK

$\left(R^{2}=0,495\right)$

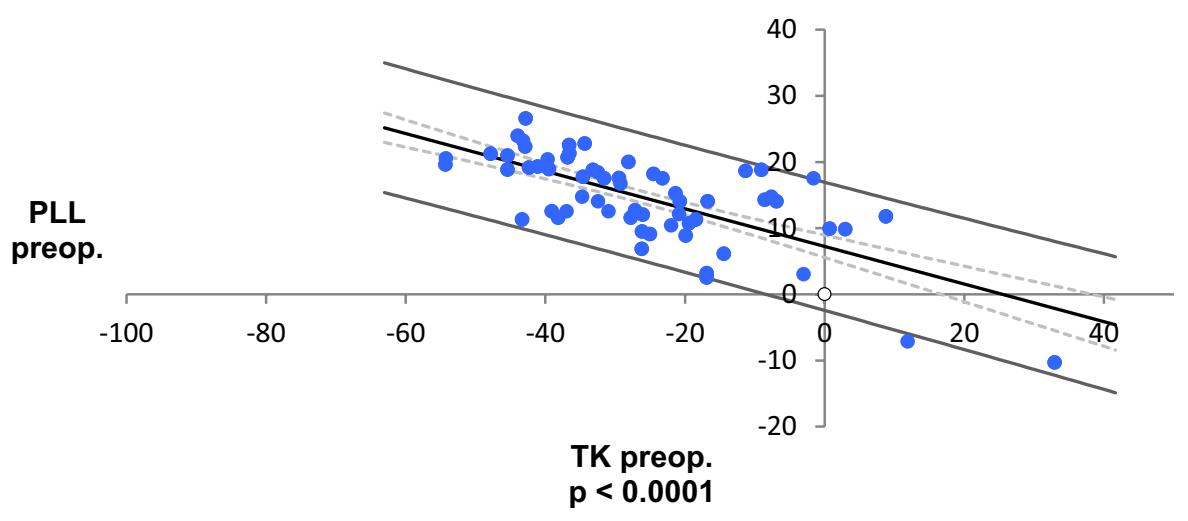

Linear régression : F-up PLL / F-up TK $\left(R^{2}=0,385\right)$

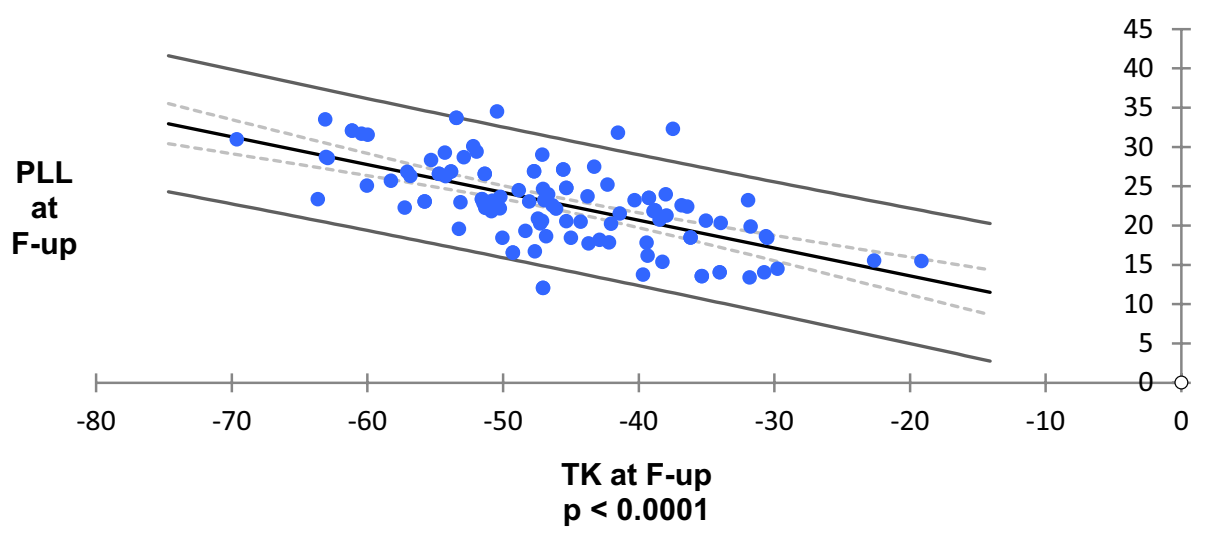

significant correlation was found between sagittal reciprocal changes [12]. Conversely, a postoperative loss in TK results in a loss of LL of the uninstrumented lumbar spine [13]. PLL has not been analyzed in these studies. Moreover, TK was measured between T4 or T5 and T12 $[12,13]$. This segmental kyphosis only reflects a part of the total kyphosis of the patient, but it does not describe what happens above or below. With measurements of the global kyphosis and lordosis, we found a significant correlation between TK and PLL (Fig. 2) and between the TK gain and the PLL gain (Fig. 3), reflecting the geometrical relationship between these angles.

PI, PT, and SS remained unchanged between preoperative and last follow-up in the two groups. This suggests that surgical increase in TK using the ST2R technique and selective fusion does not alter pelvic alignment in the long term. DLL, which is equivalent to SS, did not vary at follow-up. Increasing PLL by increasing TK is likely the only way to improve lumbar lordosis in thoracic selective fusions.

Interestingly, our results showed that improvement of lumbar lordosis occurred after the first postoperative month, while the increase in kyphosis is present at the first month.
This chronological sequence and strong statistical association suggest a casual relation. At 1 month postoperatively, there is a significant increase in PT and decrease in SS, indicating a temporary retroversion of the pelvis, offsetting the PLL increase (Table 1). This is the consequence of the new postoperative balance. As the C7 Plumb line-S1 does not change significantly, the global sagittal balance is still maintained. The initial resistance of the lumbar muscles and ligaments probably forces the patient into pelvic retroversion to maintain his balance. Then, during the following months, lumbar lordosis increases with return of pelvic parameters (SS and PT) to baseline (Fig. 4). Patients appear to require a period of adjustment to adapt to their new TK [20]. Figure 4 shows that the TK increase is initially due to the increase in the slope of the cervical spine/TK inflection point, while the retroversion of the pelvis partially cancels the LL increase. In a second step, the return of the pelvis and SS to its initial position and the maintenance of the sagittal balance allow the increase in LL and the increase in the slope of the TK/ LL inflection point. 
Fig. 3 Linear regression between gain of TK versus gain of PLL and LL. $L L$ lumbar lordosis, $P L L$ proximal lumbar lordosis, $T K$ thoracic kyphosis
Linear regression: $L L$ gain / TK gain $\left(R^{2}=0,343\right)$

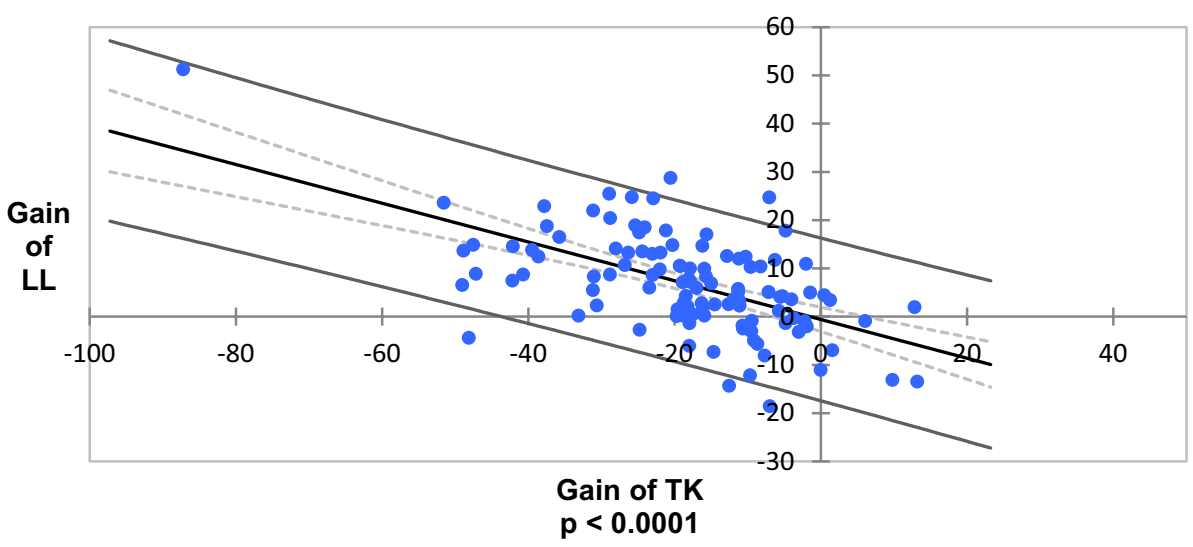

Linear regression: PLL gain / TK gain $\left(R^{2}=0,500\right)$

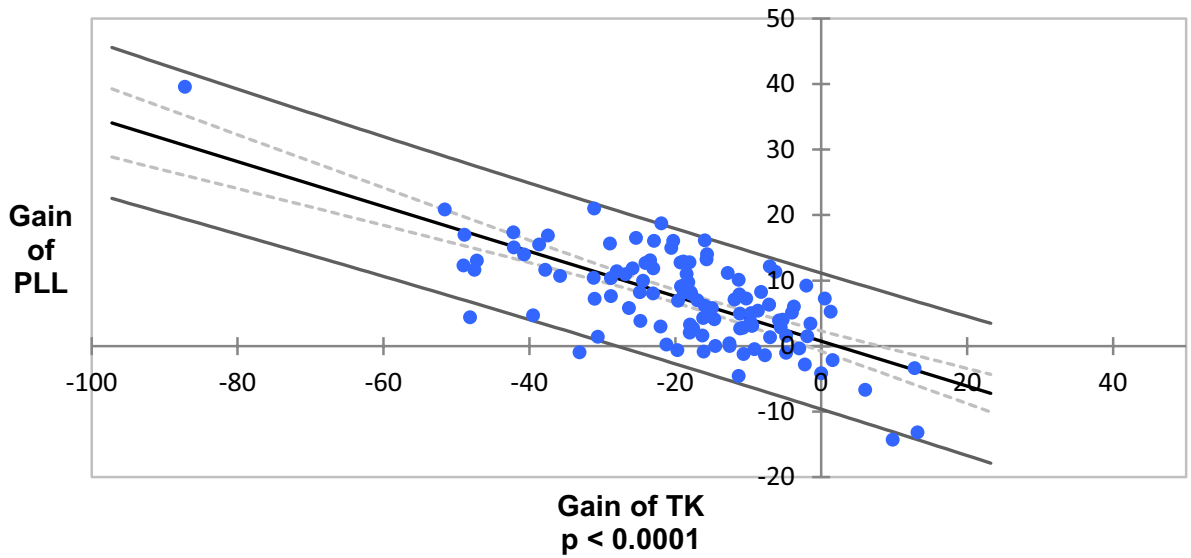

Measurement of the global kyphosis implies that TK can vary in extent after the surgical correction. In the Normo-Kyphosis group, the number of vertebrae (10 vertebrae) included in TK did not significantly change between preoperative and follow-up (Table 3). Conversely, in the Hypo-Kyphosis group, the number of vertebrae included in preoperative TK was lower (7 vertebrae) and increased significantly up to 10 vertebrae (Table 2 ). Thus, in cases of "short" thoracic kyphosis, the surgical correction can increase the extent of TK. Reciprocally, the number of vertebrae in global LL decreased significantly by 1 vertebra in both groups. The average point of inflection is thus lowered by one level from T11 to T12 and the global TK extends, on average, from $\mathrm{T} 11$ to $\mathrm{T} 2$.

This study also allows appreciation of the TK distribution between PTK and DTK. In the entire cohort, the DTK is measured at $23^{\circ}$ and global TK at $46^{\circ}$ (Table 1). TK is thus divided in half for DTK and half for PTK. This is different from kyphosis gain due to surgery, $40 \%$ of which is intended for the PLL increase. This difference can be explained by the fact that the surgical correction of TK concerns the instrumented part of TK which is only a part of the global TK.

The value of $46^{\circ}$ for postoperative TK may seem excessive. The global TK measured from the uppermost tilted vertebra to the lower most tilted vertebra is higher than a fixed TK measured between T5 or T4 and T12. T4-T12 TK does not measure what is happening above $\mathrm{T} 4$ and below T12. The normal values allowed for global TK range from 15 to $55^{\circ}[21]$.

The value of $L L$ is also high $\left(65^{\circ}\right)$ which corresponds to $15^{\circ}$ more than PI (Table 1). Aging of the spine is often associated with decrease in LL due to degenerative disk disease. Bernstein establishes thoracal flat back as a risk factor for lumbar degenerative disk disease after spinal fusion [22]. The restoration of a large LL adapted to PI constitutes a capital for the long-term future of operated AIS.

The monocentric prospective inclusions and longitudinal study, the automatic measurement of the angular values, and the measurement of the global and not segmental kyphosis and lordosis are the strengths of this work. Consideration should be taken into the lack of comparison with 


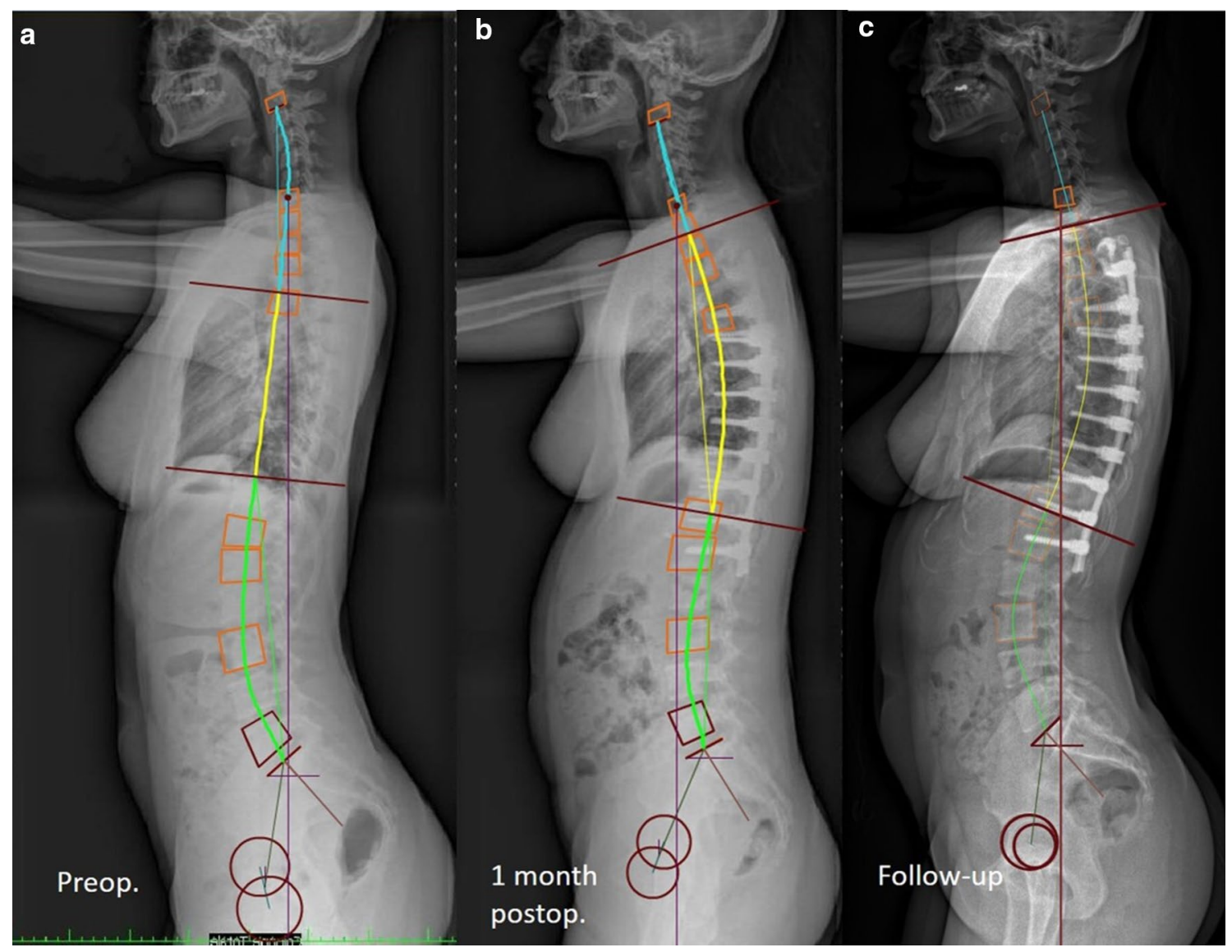

Fig. 4 Fifteen-year-old girl with Lenke type 1A AIS. a Preoperative standing sagittal X-rays. TK $=1^{\circ}, \mathrm{LL}=48^{\circ}, \mathrm{PLL}=6^{\circ}, \mathrm{PI}=51^{\circ}$, $\mathrm{PT}=9^{\circ}, \mathrm{SS}=42^{\circ}, \mathrm{C} 7-\mathrm{S} 1=+10 \mathrm{~mm}$. Number of vertebrae in $\mathrm{TK}=5$, $\mathrm{LL}=8$. b Postoperative standing sagittal X-rays. $30^{\circ}$ gain of $\mathrm{TK}$ and pelvic retroversion offsetting the $\mathrm{LL}$ increase. $\mathrm{TK}=31^{\circ}, \mathrm{LL}=38^{\circ}$,

a case series where postoperative kyphosis would have been unchanged or decreased. With this translation reduction technique, we have only one case with mild thoracic hypokyphosis $\left(19^{\circ}\right)$ at follow-up and no possibility to get a comparison case series. However, it has already been shown that the decrease in TK causes a decrease in LL [13].

Knowing the effect of surgical correction of kyphosis on LL, it is possible, in the other direction, to predict thoracic kyphosis as a function of PI and LL [23]. We propose to adapt LL to PI according to the relation $\mathrm{LL}=\mathrm{PI}+15^{\circ}$ as we found in our series. One can deduce the PLL (PLL $=L L-S S)$ and thus the DTK $(\mathrm{DTK}=\mathrm{PLL})$ to calculate the targeted $\mathrm{TK}=\mathrm{DTK}+\mathrm{PTK}$ and DTK $=$ PTK. Finally, we came up with a simple formula: $\mathrm{TK}=\mathrm{PLL} \times 2$ that to say $\mathrm{TK}=(\mathrm{LL}-\mathrm{SS}) \times 2$ and $\mathrm{TK}=\left(\mathrm{PI}+15^{\circ}-\mathrm{SS}\right) \times 2$ or $\mathrm{TK}=2\left(\mathrm{PT}+15^{\circ}\right)$. It only remains to adapt TK to the length of the instrumentation by relating it to the number of instrumented thoracic vertebrae, the global TK of this study consisting of 10 vertebrae
$\mathrm{PLL}=10^{\circ}, \mathrm{PI}=51^{\circ}, \mathrm{PT}=23^{\circ}, \mathrm{SS}=28^{\circ}, \mathrm{C} 7-\mathrm{S} 1=+40 \mathrm{~mm}$. c 3 -year follow-up standing sagittal X-rays. $18^{\circ}$ gain of LL and return to initial pelvic position. $\mathrm{TK}=36^{\circ}, \mathrm{LL}=66^{\circ}, \mathrm{PLL}=22^{\circ}, \mathrm{PI}=51^{\circ}, \mathrm{PT}=7^{\circ}$, $\mathrm{SS}=44^{\circ}, \mathrm{C} 7-\mathrm{S} 1=-2 \mathrm{~mm}$. Number of vertebrae in $\mathrm{TK}=10, \mathrm{LL}=6$

(T2-T11). Therefore, it seems necessary to use a surgical technique that can increase the TK and to be able to bend the rod with a defined and calculated angulation. This is currently possible thanks to the Patient-Specific Rod techniques.

It is now the process we use which we will have to check the effectiveness.

\section{Conclusions}

In a series of 111 AIS operated by selective posterior fusion and reduction by simultaneous translation on 2 rods, the increase in thoracic kyphosis obtained by surgery led to an increase in the uninstrumented lumbar lordosis through the increase in proximal lordosis. The gain in lumbar lordosis was close to $40 \%$ of the gain in thoracic kyphosis.

This is explained by a continuous correlation between the thoracic kyphosis and the proximal lumbar lordosis due to 
the geometric equivalence between distal thoracic kyphosis and proximal lumbar lordosis.

This allows for the calculation of thoracic kyphosis required during surgical correction to adapt the lumbar lordosis to the pelvic incidence of the patient, and then bend the rod with a suitable contour.

Funding Jean-Luc Clément has received consultancy fees and financial support for attending symposia (unrelated to this study) from Médicrea. Federico Solla has received financial support for attending symposia (unrelated to this study) from Médicrea. (Médicréa International, Rillieux La Pape, France).

\section{Compliance with ethical standards}

Conflict of interest The authors declare that they have no conflict of interest.

Open Access This article is distributed under the terms of the Creative Commons Attribution 4.0 International License (http://creativeco mmons.org/licenses/by/4.0/), which permits unrestricted use, distribution, and reproduction in any medium, provided you give appropriate credit to the original author(s) and the source, provide a link to the Creative Commons license, and indicate if changes were made.

\section{References}

1. Kim YJ, Lenke LG, Kim J, Bridwell KH, Cho SK, Cheh G, Sides B (2006) Comparative analysis of pedicle screw versus hybrid instrumentation in posterior spinal fusion of adolescent idiopathic scoliosis. Spine 31:291-298. https://doi.org/10.1097/01. BRS.0000197865.20803.d4

2. Lowenstein JE, Matsumoto H, Vitale MG, Weidenbaum M, Gomez JA, Lee FY, Hyman JE, Roye DP Jr (2007) Coronal and sagittal plane correction in adolescent idiopathic scoliosis: a comparison between all pedicle screw versus hybrid thoracic hook lumbar screw constructs. Spine 32:448-452. https://doi. org/10.1097/01.BRS.0000255030.78293.fd

3. Lehman RA Jr, Lenke LG, Keeler KA, Kim YJ, Buchowski JM, Cheh G, Kuhns CA, Bridwell KH (2008) Operative treatment of adolescent idiopathic scoliosis with posterior pedicle screwonly constructs: minimum three-year follow-up of one hundred fourteen cases. Spine 33:1598-1604. https://doi.org/10.1097/ BRS.0b01

4. Quan GMY, Gibson MJ (2010) Correction of Main Thoracic Adolescent Idiopathic Scoliosis Using Pedicle Screw Instrumentation Does Higher Implant Density Improve Correction? Spine 35:562-567. https://doi.org/10.1097/BRS.0b013e3181b4af34

5. Fletcher ND, Hopkins J, McClung A, Browne R, Sucato DJ (2011) Residual thoracic hypokyphosis following posterior spinal fusion and instrumentation in adolescent idiopathic scoliosis: risk factors and clinical ramifications. Spine 37:200-206. https://doi. org/10.1097/BRS.0b013e318216106c

6. Mladenov KV, Vaeterlein C, Stuecker R (2011) Selective posterior thoracic fusion by means of direct vertebral derotation in adolescent idiopathic scoliosis: effects on the sagittal alignment. Eur Spine J 20:1114-1117. https://doi.org/10.1007/s0058 6-011-1740-7

7. Asher M, Lai SM, Burton D, Manna B, Cooper A (2004) Safety and efficacy of Isola instrumentation and arthrodesis for adolescent idiopathic scoliosis: two- to 12 -year follow-up. Spine 29(18):2013-2023

8. Clement JL, Chau E, Kimkpe C, Vallade MJ (2008) Restoration of thoracic kyphosis by posterior instrumentation in adolescent idiopathic scoliosis: comparative radiographic analysis of two methods of reduction. Spine 33:1579-1587. https://doi.org/10.1097/ BRS.0b013e31817886be

9. Ilharreborde B, Pesenti S, Ferrero E, Accadbled F, Jouve JL, Sales De Gauzy J, Mazda K (2018) Correction of hypokyphosis in thoracic adolescent idiopathic scoliosis using sublaminar bands: a 3D multicenter study. Eur Spine J 27:350-357. https:// doi.org/10.1007/s00586-017-5166-8

10. Clément JL, Chau E, Vallade MJ, Geoffray A (2011) Simultaneous translation on two rods is an effective method for correction of hypokyphosis in AIS: radiographic results of 24 hypokyphotic thoracic scoliosis with 2 years minimum follow-up. Eur Spine J 20:1149-1156. https://doi.org/10.1007/s00586-011-1779-5

11. Clement JL, Chau E, Geoffray A, Vallade MJ (2012) Simultaneous translation on two rods to treat adolescent idiopathic scoliosis. radiographic results in coronal, sagittal, and transverse plane of a series of 62 patients with a minimum follow-up of two years. Spine 37:184-192. https://doi.org/10.1097/BRS.0b013e3182 155104

12. Blondel B, Lafage V, Schwab F, Farcy JP, Bollini G, Jouve JL (2012) Reciprocal sagittal alignment changes after posterior fusion in the setting of adolescent idiopathic scoliosis. Eur Spine J 21:1964-1971. https://doi.org/10.1007/s00586-012-2399-4

13. Newton PO, Yaszay B, Upasani VV, Pawelek JB, Bastrom TP, Lenke LG, Lowe T, Crawford A, Betz R, Lonner B (2010) Preservation of thoracic kyphosis is critical to maintain lumbar lordosis in the surgical treatment of adolescent idiopathic scoliosis. Spine 35:1365-1370. https://doi.org/10.1097/BRS.0b013e3181dccd63

14. Clément JL, Geoffray A, Yagoubi F, Chau E, Solla F, Oborocianu I, Rampal V (2013) Relationship between thoracic hypokyphosis, lumbar lordosis and sagittal pelvic parameters in adolescent idiopathic scoliosis. Eur Spine J 22:2414-2420. https://doi. org/10.1007/s00586-013-2852-z

15. Lenke LG, Edwards CC 2nd, Bridwell KH (2003) The Lenke classification of adolescent idiopathic scoliosis: how it organizes curve patterns as a template to perform selective fusions of the spine. Spine 28:S199-S207. https://doi.org/10.1097/01.brs.00000 92216.16155.33

16. Maillot C, Ferrero E, Fort D, Heyberger C, Le Huec C (2015) Reproducibility and repeatability of a new computerized software for sagittal spinopelvic and scoliosis curvature radiologic measurements: Keops. Eur Spine J 24:1574-1581. https://doi. org/10.1007/s00586-015-3817-1

17. Berthonnaud E, Dimnet J, Roussouly P, Labelle H (2005) Analysis of the sagittal balance of the spine and pelvis using shape and orientation parameters. J Spinal Disord Tech 18:40-47

18. Vaz G, Roussouly P, Berthonnaud E et al (2002) Sagittal morphology and equilibrium of pelvis and spine. Eur Spine J 11:80-87. https://doi.org/10.1007/s005860000224

19. Sucato DJ, Agrawal S, O'brien MF, Lowe TG, Richards SB SB, Lenke L (2008) Restoration of thoracic kyphosis after operative treatment of adolescent idiopathic scoliosis: a multicenter comparison of three surgical approaches. Spine 33:2630-2636. https ://doi.org/10.1097/BRS.0b013e3181880498

20. La Maida GA, Zottarelli L, Mineo GV, Misaggi B (2013) Sagittal balance in adolescent idiopathic scoliosis: radiographic study of spino-pelvic compensation after surgery. Eur Spine J 22(S6):859-867

21. Winter RB, Lonstein JE, Denis F (2009) Sagittal spinal alignment: the true measurement, norms, and description of correction for 
thoracic kyphosis. J Spinal Disord Tech. 22:311-314. https://doi. org/10.1097/BSD.0b013e31817dfcc3

22. Bernstein P, Hentschel S, Platzek I, Huhne S, Ettrich U, Hartmann A, Seifert J (2014) Thoracal flat back is a risk factor for lumbar disc degeneration after scoliosis surgery. Spine J 14:925-932
23. Liu S, Zhang Y, Bao H, Yan P, Zhu Z, Liu Z, Qian B, Qiu $Y$ (2018) Could pelvic parameters determine optimal postoperative thoracic kyphosis in Lenke type 1 AIS patients? BMC Musculoskeletal Disorders 19:74. https://doi.org/10.1186/s1289 $1-018-1992-z$

\section{Affiliations}

\section{Jean-Luc Clément ${ }^{1}\left[\right.$ (] $\cdot$ Yann Pelletier ${ }^{1} \cdot$ Federico Solla $^{1} \cdot$ Virginie Rampal $^{1}$}

$\triangle$ Jean-Luc Clément

clement.jluc@wanadoo.fr;

clement.jl@pediatrie-chulenval-nice.fr
1 Pediatric Orthopaedic Department, Hôpitaux pédiatriques de Nice CHU LENVAL, 57 Avenue de la Californie, Nice, France 